\title{
Synthesis of Novel Halogenated Angular Azaphenothiazinones of Biological Interest
}

\author{
Evelyn U Godwin Nwakwasi ${ }^{1}$, Uchechukwu C Okoro ${ }^{2}$, Mercy A Ezeokonkwo ${ }^{2}$, Fidelia N Ibeanu ${ }^{3}$ and Ifeoma C \\ $\mathrm{Ugwu}^{4}$ \\ ${ }^{1}$ Department of Chemistry, Gregory University Uturu Abia State, Nigeria \\ ${ }^{2}$ Department of Pure and Industrial Chemistry, University of Nigeria Nsukka, Nigeria \\ ${ }^{3}$ School of General Studies, Natural Science Unit, University of Nigeria Nsukka, Nigeria \\ ${ }^{4}$ Department of Veterinary Pathology and Microbiology, Faculty of Veterinary Medicine, University of Nigeria Nsukka, Nigeria
}

Submission: February 12, 2018; Published: February 27, 2018

${ }^{*}$ Corresponding author: Evelyn U Godwin Nwakwasi, Department of Chemistry, Gregory University Uturu Abia State, Nigeria, Tel: 234803873

7824, Email: evelynnwakwasi@yahoo.com

\begin{abstract}
In a continued search for new biologically active angular phenothiazine compounds, novel non-linear polycyclic phenothiazine halogeno derivatives have been synthesized via coupling reactions. The coupling of equimolar mixture of 2-amino-5-bromopyrazine-3[4H]-thione and 6,7-dibromo-5,8-quninolinequinone under anhydrous condition, furnished two isomers, 6,9-dibromo-1, 8, 11-traiza-5H-benzo[a]phenothiazin5-one and 6,9-dibromo-4, 8, 11-triaza-5H-benzo[a]phenothiazin-5-one. These compounds were screened for their antimicrobial activity against E. coli, Staphylococcus spp, Bacillus spp. and Pseudomonas aeruginosa at varying concentrations using Agar-well diffusion method and the results showed that these phenothiazine moieties had significant biological activity and inhibited the growth of these bacterial isolates even at low concentrations. Structures were assigned based on spectroscopic data and elemental analysis.
\end{abstract}

Keywords: Angular phenothiazines; Coupling; Biological activity; Halogeno derivatives

\section{Introduction}

A good number of phenothiazine derivatives have been known for their biological activities, yet considerable attention is still paid to them as a result of their varied uses in medicine which have prompted greater focus on phenothiazine moieties especially the aza analogues [1-3]. For instance, prothipendyl, 1 , the 1-azaphenothiazine analog of promazine is found to be a superior drug to chlorpromazine, 2 , in the treatment of mental disorders particularly in acute psychosis complicated with latent epilepsy [3] (Figure 1). This and other reports led to redirection of attention once more to azaphenothiazine ring systems as they aroused greater interest in the aza analogues of phenothiazine [4]. Phenothiazine derivatives have been found to possess potent wide spectrum CNS activities viz: anticonvulsant, antipsychotic, antidepressant and anti-neuroleptics [5-9]. Besides, they also possess potent anti-tubercular, antitumor, anti-histaminic and antibacterial activities among others [10-13]. Most reports on the pharmacology activities of phenothiazines were centred on the linear derivatives, only few reports have appeared in the literature on the angular type especially the non-linear aza analogues [14-16]. In this direction, we report the bactericide activity of newly synthesized angular aza phenothiazine derivatives against E.coli, Staphylococcus pseudointermedius, Staphylococcus scuiri, Bacillus spp and Pseudomonas aeruginosa.<smiles>CN(C)Cn1c2ncccc2sc2ccccc2n1-c1ccccc1N(C)C</smiles>

Results and Discussion

Two key functional intermediates were used in this work namely, 2-amino-5-bromopyrazine-3[4H]-thione, 3 , and 6,7-dibromo-5,8-quinolinequinone, 4 (Figure 2). Intermediate 3 was obtained in good yield according to literatureas colorless needles by treating 2 -aminopyrazine, 5 , with bromine in glacial 
acetic acid at 0 to -5 oC followed by thiation using sodium hydrosulphide in methanol and recrystallization using DMF (Norit) (Scheme 1) $[17,18]$.<smiles>Nc1ncc(Br)nc1S</smiles>

3<smiles>O=C1C(Br)=C(Br)C(=O)c2ncccc21</smiles>

4
Figure 2.

Intermediate 4 wasprepared by converting8-hydroxyquinoline, 6 , to the nitroso moiety, 7 which was subsequently reduced under nitrogen atmosphere with sodium dithionite to 5-amino-8hydroxyquinoline sulphate, 8 [19-21]. This reduced product was treated with $24 \%$ hydrobromic acid and aqueous sodium bromate to furnish the intermediate of interest, 4 (Scheme 2).

Base mediated condensation (Scheme 3) using equimolar mixture of compound 3 and 6,7-dibromo-5, 8-quinoquinone, 4 furnished two isomers, 6,9-dibromo-1, 8, 11-triaza-5Hbenzo[a]phenothiazin-5-one, 9 and 6, 9-dibromo-4, 8, 11-triaza5H-benzo[a]phenothiazin-5-one, 10. The two isomers were separated by column chromatography and were identified on the basis of Uv-Vis, Ir and NMR spectra. The elemental analysis of the found and the calculated also agreed. This formation of angular polycyclic phenothiazinone heterocycles by base mediated reaction of ortho amino heterocyclic thiones and halogenated quinolinequinones is consistent with previous reports in the literature [8-14].<smiles></smiles>

Scheme 1: Synthesis of intermediate 3.

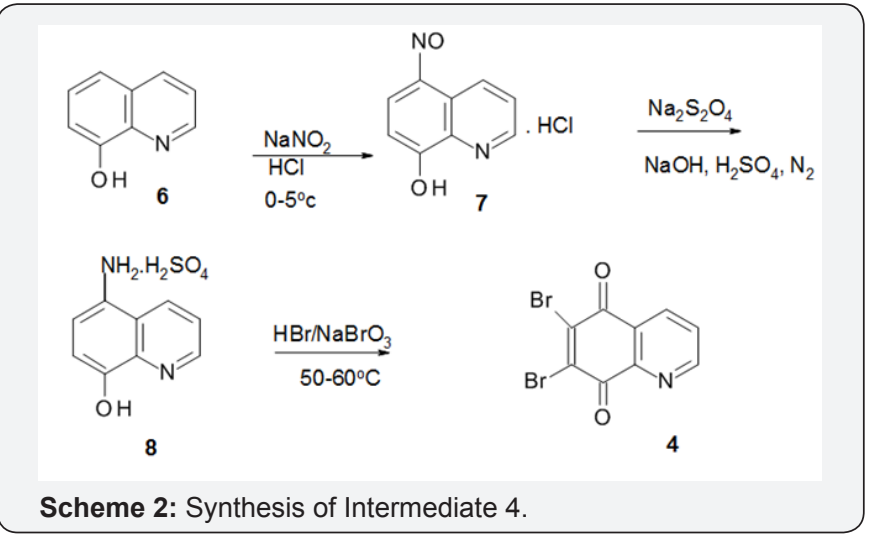

Scheme 3: Synthesis of Compounds 9 and 10 .

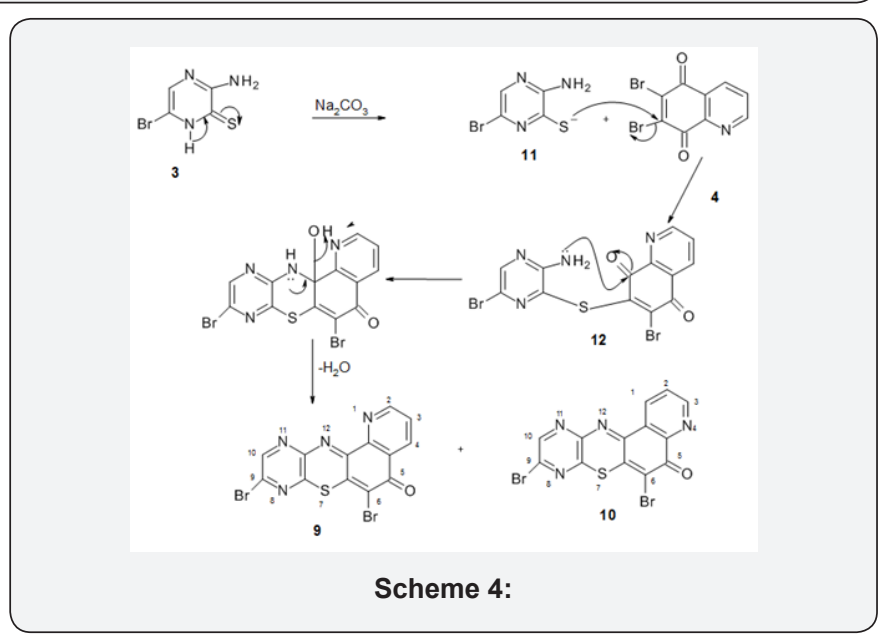

The possible mechanism for this reaction is rationalized as follows (Scheme 4): the mercaptide ion, 11, mounts a nucleophilic attack at the 7-bromo position of compound 7 leading to the formation of the diaryl sulphide, 12 . The electron-rich amino group mounts another nucleophilic attack at the carbonyl carbon of the quinolinequinone moiety which leads to elimination of water molecule (condensation) resulting to the formation of compounds 9 and 10 .

Due to considerable biological and pharmaceutical activities of quinoneimines, the antibacterial activity of these novel non-linear phenothiazine derivatives was evaluated. 
This was largely as a result of the fact that the precursors, 8-hydroxyquinolinequinone, 6, and 6, 7-dibromo-5,8quinolinequinone, 4, are known to have fungistatic and bacteriostatic activities [19-22]. An effective approach of antimicrobial therapy of an infection is based on the isolation and identification of the infected organism and determining its sensitivity to antimicrobial drugs. The microorganisms tested were E.coli (strains used were coded Eco 3, Eco 4 and Eco 12), Staphylococcus pseudointermedius and Staphylococcus scuiri (G101 and G84 respectively), Bacillus spp. and Pseudomonas aerugionsa. The assay was conducted using agar-well diffusion method in which a $20 \mathrm{mg} / \mathrm{ml}$ concentration of each compound was constituted by dissolving $0.04 \mathrm{~g}$ of each compound in 2 $\mathrm{ml}$ of dimethyl sulfoxide (DMSO) [23]. A single colony of each test isolate was suspended in $2 \mathrm{ml}$ of sterile nutrients broth. Inoculation was done followed by incubation at 37oC for 24 $\mathrm{hr}$ after which the plates were observed for inhibition zones around the wells. The diameters of the zones were measured with metre rule to the nearest whole millimetre. The result of the preliminary screening of the novel compounds tested against some Gram negative and Gram positive bacteria are shown in Table 1.

Table 1: Results of Antibacterial susceptibility test (tested with $20 \mathrm{mg} / \mathrm{ml}$ of each compound).

\begin{tabular}{|c|c|c|c|c|c|c|c|}
\hline Cpd & G101 & G84 & Eco 3 & Eco 4 & Eco 12 & $\begin{array}{c}\text { Bacillus } \\
\text { Spp. }\end{array}$ & $\begin{array}{c}\text { Pseudomonas } \\
\text { Aeruginosa }\end{array}$ \\
\hline 9 & 18 & 19 & 11 & 11 & 12 & 17 & 0 \\
\hline 10 & 21 & 17 & 11 & 0 & 0 & 16 & 0 \\
\hline
\end{tabular}

Cpd = compound.

The figures in Table 1 show the inhibition zone diameter produced by each compound against each bacterial organism at $20 \mathrm{mg} / \mathrm{ml}$ concentration. The IZD ranged between 0 and 21 $\mathrm{mm}$ in diameter; the higher the IZD, the higher the sensitivity. The compounds showed significant activity against the test organisms except Pseudomonas aeruginosa which was resistant to both isomers; Eco 4 and Eco 12 were resistant to compound 10. Minimum inhibitory concentration of the compounds was also determined by the agar-well diffusion method with various Table 2: Result of Minimum Inhibitory Concentration (MIC) $(\mathrm{mg} / \mathrm{ml})$ of the Synthesized Compounds and Some Standard Drugs.

\begin{tabular}{|c|c|c|c|}
\hline Compound/Drug & Eco3 & G84 & Bacillus spp. \\
\hline 9 & 20 & 5 & 1.25 \\
\hline 10 & 20 & 5 & 1.25 \\
\hline Ampicillin & 100 & 2.5 & 1.25 \\
\hline Gentamycin & 6.25 & 2.5 & 0.15625 \\
\hline
\end{tabular}

The antimicrobial activity of these compounds was compared with those of some standard drugs. Table 2 below gives the result of Minimum Inhibitory Concentration (MIC) of the synthesized compounds, Ampicillin and Gentamycin (standard drugs) against Eco 3, G84 and Baccilus spp. The MIC for the compounds against Eco 3, G84 and Bacillus spp. ranged from $1.25 \mathrm{mg} / \mathrm{ml}$ to $20 \mathrm{mg} / \mathrm{ml}$. For instance, the MIC for Eco 3 for compounds 9 and 10 is $20 \mathrm{mg} / \mathrm{ml}$ because there was no inhibition at the next concentration which is $10 \mathrm{mg} / \mathrm{ml}$. It became necessary to compare the MICs of the synthesized compounds with those of some standard antibiotics against the microbes tested. Ampicillin and Gentamycin were used because they are standard drugs used for treating such strains of microorganisms; plain agar (i.e, without any of the test compounds) was also spot-inoculated to serve as the control because it had no effect against the isolates as it showed no zone of inhibition. The MIC of the standard drugs ranged between $100 \mathrm{mg} / \mathrm{ml}$ and $0.15625 \mathrm{mg} / \mathrm{ml}$. From Table 2 is synthesized phenothiazine derivatives were active against concentrations ranging between $20 \mathrm{mg} / \mathrm{ml}$ and $0.15625 \mathrm{mg} / \mathrm{ml}$ and was compared with those of some standard drugs. Minimum inhibitory concentration is the minimal concentration of drug that inhibits visible growth after overnight incubation [23-25]. The lowest concentration of each compound that produced no zone was regarded as MIC. Hence, the essence of MIC is to determine the least concentration of drug that can inhibit the growth of the micro-organism.

Eco 3 at lower concentrations than Ampicillin and compared favourably well in their resistance against G84 and Bacillus spp. showing that the synthesized phenothiazine compounds are highly biologically active; hence, they may be of pharmaceutical interest.

\section{Conclusion}

We have shown that these angular (non-linear) azaphenothiazines are pharmaco-actively effective against some strains of bacteria thereby increasing the number of biologically active phenothiazine derivatives. More so, some of the isolates are methicillin resistant and they are imagined problems because they are difficult to treat and they infect humans and animals. However, we are glad that these synthesized compounds resisted them effectively even at very low concentrations. However, the possible industrial values of these heterocycles need investigation as they are deeply coloured and phenothiazines are known to be extensively used as dyes and pigments. 


\section{Experimental}

\section{General Information}

Melting points were taken using Fisher-Johns melting point apparatus and they remain uncorrected. Compounds were characterized by HNMR, CNMR, IR spectroscopy, UV/ Visible spectroscopy and elemental analysis. UV-Visible spectra were recorded on a JENWAY 6405 UV/VIS Spectrophotometer using matched $1 \mathrm{~cm}$ quartz cells, Department of Pure and Industrial Chemistry, University of Nigeria Nsukka; IR spectra on a SHIMADZU FTIR-8400S FOURIER TRANSFORM INFRARED SPECTROPHOTOMETER (KBr Pellets), (NARICT, ZARIA). Nuclear magnetic resonance (HNMR and CNMR) spectra were determined using Varian NMR Mercury-200BB (Central Science Lab. Obafemi Awolowo University Ife). Chemical shifts are recorded on the $\delta$-scale (neat). The elemental analyses were done at the Central Science laboratory, University of Cairo, Egypt on a CE440 Elemental Analyzer. The antimicrobial screening was done at the Faculty of Veterinary Medicine, University of Nigeria, Nsukka.

\section{8-Hydroxy-5-nitrosoquinoline hydrochloride, 10}

This compound was prepared following the procedure of Pratt and Drake. To a solution of 8-hydroxyquinoline (58g, 0.4 $\mathrm{mol}$ ) in $200 \mathrm{ml}$ of water, $75 \mathrm{ml}$ of concentrated $\mathrm{HCl}$ and $200 \mathrm{~g}$ of ice was added a solution of $30 \mathrm{~g}$ of sodium nitrite in $100 \mathrm{ml}$ of water in portions with vigorous shaking over $1 \mathrm{hr}$ at 0 to $4 \mathrm{OC}$. The mixture was allowed to stand overnight at $00 \mathrm{C}$ before the product was filtered off and washed with cold water. The product was air-dried giving a yield of $76 \mathrm{~g}(87 \%)$ of the hydrochloride of 8-hydroxy-5-nitrosoquinoline (m.p, 181-183 0C, dec) as fine yellow compound. The compound loses its brightness in time and darkens due to auto-oxidation.

\section{5-Amino-8-hydroxyquinoline sulphate, 14}

$20 \mathrm{~g}(0.11 \mathrm{~mol})$ of the freshly prepared hydrochloride of 8-hydroxy5-nitrosoquinoline was dissolved in a mixture of water $(80 \mathrm{ml})$ and $5 \mathrm{M} \mathrm{NaOH}(130 \mathrm{ml})$ placed in a three-necked flask $(500 \mathrm{ml})$ equipped with a long magnetic bar. The entire mixture was warmed to $40 \mathrm{oC}$ with stirring and sodium dithionite ( $48 \mathrm{~g}$ ) was added portion wise. The temperature of the solution rose spontaneously to $75-80 \mathrm{oC}$ and a rapid stream of nitrogen were introduced into the solution. The solution was allowed to cool slowly to about $50 \mathrm{oC}$ and $6 \mathrm{M}$ sulphuric acid $(125 \mathrm{ml})$ was then added which led to evolution of sulphur dioxide. When the evolution of sulphur dioxide had subsided the solution was maintained under diminished pressure (pressure of the nitrogen gas reduced) with magnetic stirring until most of the dissolved gases had been removed. The mixture was cooled in an ice-bath and the resulting precipitate filtered without washing. Reddishbrown crystals of 5-amino-8-hydroxyquinoline sulphate (16.5 g, 82.5\%) were obtained, m.p 218-219oC (Lit. 220oC).

\section{6,7-Dibromo-5, 8-quinolinequinone, 7}

Compound 4 was prepared using combined literature [2628]. 5-Amino-8-hydroxyquinoline sulphate $(54 \mathrm{~g}, 0.34 \mathrm{~mol}$ ) was dissolved in $24 \%$ hydrobromic acid $(400 \mathrm{ml})$ in a 1-litre three-necked flask equipped with reflux condenser, quick fit thermometer, magnetic bar and a dropping funnel. The reaction mixture was heated to $50 \mathrm{oC}$. A solution of sodium bromated 38.5 g, $0.225 \mathrm{~mol})$ in water $(150 \mathrm{ml})$ was added at such a rate that the temperature does not exceed 50-60oC. After the addition, the reaction mixture was heated at that temperature with gentle stirring for $0.5 \mathrm{~h}(30 \mathrm{~min})$ and then cooled. The cooled mixture was poured onto ice (500 g) and further chilled in an ice-salt mixture. The resulting precipitate was filtered and recrystallized from ethanol to give yellow precipitate of 6,7-dibromo-5,8quinolinequinone (71.3 g, 66\%); m.p 242-243oC (Lit. 243245oC).

UV-Vis (MeOH): $\lambda \max 265$ (3.69), 290 (3.92), 345 (3.45) and $505(2.20) \mathrm{nm}$.

Ir (KBr): umax 3093, 1686, 1541, 1289, 664, $662 \mathrm{~cm}-1$

\section{2-Amino-3,5-dibromopyrazine}

This compound was prepared following Okafor and Okoro's procedure. 2-Aminopyrazine $(9.5 \mathrm{~g}, 100 \mathrm{mmol})$ was placed in a reaction flask containing glacial acetic acid $(70 \mathrm{ml})$ and warmed on a steam bath until it dissolved. Sodium acetate trihydrate (33 g, $243 \mathrm{mmol}$ ) was added with constant swirling. The slurry was stirred in an ice-salt bath maintained at $-50 \mathrm{C}$ and bromine $(16 \mathrm{ml})$ was added dropwise over a $4 \mathrm{~h}$ period (if the bromine addition was speeded up the reaction became turbulent and potentially hazardous). The mixture was stirred in the ice bath for $2 \mathrm{~h}$ and then at room temperature for $24 \mathrm{~h}$. It was then poured into ice (50 g) and neutralized with concentrated ammonia $(\mathrm{pH}$ 8). The crude product were collected and recrystallized from methanol (Norit) to give colourless needles of 2-amino3,5-dibromopyrazine (16.8 g, 66\%), m.p 113-114oC (Lit. 114115oC) (Figure 3).

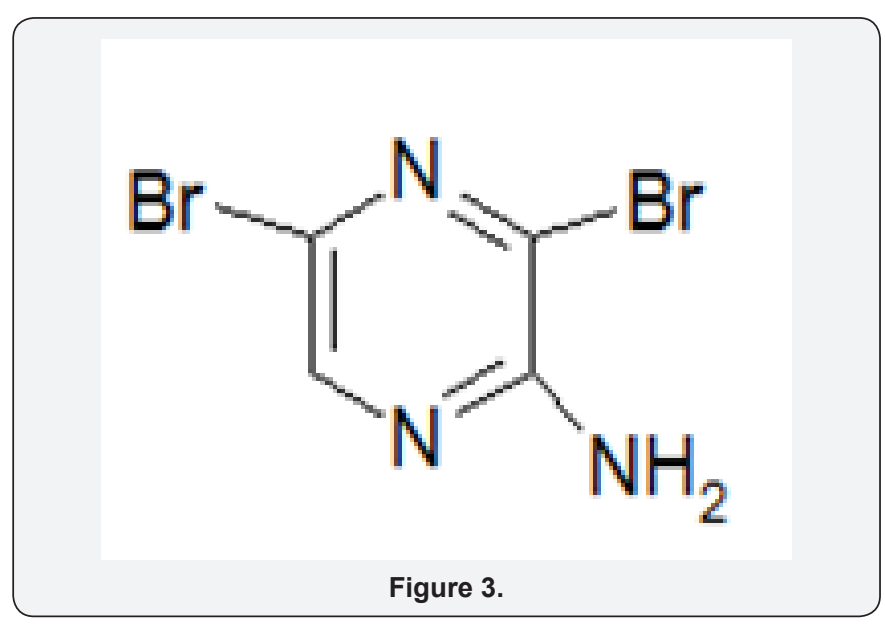




\section{2-Amino-5-bromopyrazine-3[4H]-thione, 5}

A mixture of 2-amino-3,5-dibromopyrazine (7.69g, 30 mmol) and sodium hydrosulphide (13.33g, $238 \mathrm{mmol}$ ) was added to methanol $(60 \mathrm{ml})$ and the mixture was refluxed for 4.5h. Methanol was then removed by distillation and the residual dark moist solid was dissolved in water $(150 \mathrm{ml})$, treated with activated charcoal, boiled and filtered. The filtrate was cooled and the product filtered. Recrystallization from DMF (Norit) yielded pure 2-amino-5-bromopyrazine-3[4H]-thione $(3.75 \mathrm{~g}$, $61 \%$ ) as a yellow solid, m.p 209-211oC (dec); (lit. 208-210oC).

6,9-Dibromo-1,8,11-triaza-5H-benzo[a]phenothiazin5-one, 7 and 6,9-dibromo-4,8,11-triaza-5H-benzo[a] phenothiazin-5-one, 8

A mixture of benzene $(40 \mathrm{ml})$ and dimethylformamide $(5 \mathrm{ml})$ was added to 2-amino-5-bromopyrazine-3[4H]-thione $(1.03 \mathrm{~g}$, $5 \mathrm{mmol}$ ) mixed with anhydrous sodium carbonate (1.06 g, 10 $\mathrm{mmol}$ ) in a100 $\mathrm{ml}$ three-necked flask equipped with a magnetic stirring bar. The entire mixture was refluxed on a water-bath at $70-750 \mathrm{C}$ for $45 \mathrm{~min}$. while stirring. Then, 6,7-dibromo5-8-quinolinequinone (1.59 g, $5 \mathrm{mmol})$ was added and the stirring continued for $6 \mathrm{~h}$ while the refluxing temperature was maintained at $70-750 \mathrm{c}$. At the end of the reflux period, the solvent was evaporated and the reddish-brown crude product was column chromatographed using methanol-acetone (2:1) as eluting solvent. From the first fraction, a dark red solid was obtained, compound 7. It weighed $0.68 \mathrm{~g}(32.1 \%)$ and melted at $148-150 \mathrm{oC}$ (dec.) The second fraction gave compound 8 as a brown solid which weighed $1.23 \mathrm{~g} \mathrm{(58.0 \% )}$ and melted at 291293oC (dec).

UV-Vis $(\mathrm{MeOH})$ for Compound 7: $\lambda \max 222.2(4.57)$, 247.4(4.82), 341.8(4.50) nm.

Ir (KBr): vmax 3085, 1638, 1553, 1262, 740cm-1

HNMR (DMSO): $\delta 8.2(1 \mathrm{H}, \mathrm{s}), 7.0(3 \mathrm{H}, \mathrm{Ar}-\mathrm{H})$,

CNMR (DMSO): $\delta 186(\mathrm{C}=0), 153(\mathrm{C}-2), 143(\mathrm{C}-10), 123(\mathrm{C}-3)$, 120 (C-6), 38.6- 41.1(DMSO)

Anal. Calcld for C13H4N4Br2SO: C, 36.80; H, 0.94; N, 13.21; $\mathrm{Br}, 37.74 ; \mathrm{S}, 7.55$;

Found: C13H4N4Br2SO: C, 36.80; H, 0.96; N, 13.28; $\mathrm{Br}, 37.81, \mathrm{~S}, 7.60$

UV-Vis (MeOH) for Compound 8: $\lambda \max 275(3.80), 340(4.22)$ $\mathrm{nm}$.

Ir (KBr): umax 3169, 1692, 1315, 1205, $691 \mathrm{~cm}-1$

HNMR (DMSO): $\delta 2.6$ (DMSO)

CNMR (DMSO): $\delta 38.8-40.7($ DMSO)

Anal. Calcld for C13H4N4Br2SO: C, 36.80; H, 0.94; N, 13.21; Br, 37.74; S, 7.55;
Found: C13H4N4Br2SO: C, 36.68; H, 0.91; N, 13.25; Br, 37.89; S, 7.59

\section{Evaluation of the Synthesized Angular Phenothiazinones for Antibacterial Activity}

The assay was conducted using agar-well diffusion method [23]. An $20 \mathrm{mg} / \mathrm{ml}$ concentration of each compound was constituted by dissolving $0.04 \mathrm{~g}$ of each in $2 \mathrm{ml}$ dimethyl sulfoxide. A single colony of each test isolate was suspended in $2 \mathrm{ml}$ of sterile nutrient broth. The suspension of each isolate was standardized by adjusting to correspond to 0.5 McFarland turbidity standards corresponding to approximately $108 \mathrm{cfu} /$ $\mathrm{ml}$ and used to inoculate the surface of the iso-sensitest nutrient agar and the excess fluid drained into discard pot containing disinfectant. The inoculated agar surface was allowed to dry and the plates appropriately labelled. Using a cork borer of $6 \mathrm{~mm}$ in diameter, wells were bored in the inoculated iso-sensitest nutrient agar. With a micropipette, $50 \mu \mathrm{l}$ of each test compound solution was delivered into each well. The plates were left on the bench for 30 minutes to allow the compound to diffuse into the agar. Thereafter, the plates were incubated at $37 \mathrm{oC}$ for $24 \mathrm{~h}$. After incubation, the plates were observed for inhibition zones around the wells. The diameters of the zones were measured with metre rule to the nearest whole millimetre.

\section{Determination of Minimum Inhibitory Concentration (MIC) of the Synthesized Angular Phenothiazinones}

This was carried out using agar dilution following the procedure outlined by Clinical Laboratory Standards Institute [25]. Sterile test tubes were arranged on a test tube rack and 1 $\mathrm{ml}$ of DMSO was dispensed into each of them. From the stock compound solutions, $1 \mathrm{ml}$ was transferred into the first test tube and two-fold serial dilution of each compound solution was carried out and the resultant concentration in the test tubes were $10,5,2.5,1.25,0.625,0.3125$, and $0.15625(\mathrm{mg} / \mathrm{ml})($ i.e, graded concentrations of the compounds) [26]. A single colony of each test isolate was suspended in $2 \mathrm{ml}$ of sterile nutrient broth. The suspension of each isolate was standardized and used to inoculate the surface of the nutrient agar and the excess fluid drained into discard pot containing disinfectant.

The inoculated agar surface was allowed to dry and the plates appropriately labelled. Using a cork borer of $6 \mathrm{~mm}$ in diameter, wells were bored in the inoculated nutrient agar. With a micropipette, $50 \mu \mathrm{l}$ of each test compound solution was delivered into each well. The plates were left on the bench for 30 minutes to allow the compound to diffuse into the agar. Thereafter, the plates were incubated at $37 \mathrm{oC}$ for $24 \mathrm{~h}$. After incubation, the plates were observed for inhibition zones around the wells. The diameters of the zones were measured with meter rule to the nearest whole millimeter. MIC was taken as the lowest concentration of the compounds that resulted in no visible growth on the surface of the agar. 


\section{References}

1. Gordon M, Craig PN, Zirkle CJ (1964) Molecular modification in Drug Design. American Chemical Society, Washington, USA, pp. 114-161.

2. Okafor CO, Steenberg ML, Buckley JP (1977) Studies in the heterocyclic series: XIII, New CNS-depressants derived from 1,9-Diazaphenoxazine and two isomeric triazaphenothiazine Ring Systems. Eur J Med Chem Clinica Therapeutica 12(3): 249-256.

3. Okafor CO, Uche IO, Akpanisi LES (1981) Studies in the Heterocyclic series, XXI, A Novel Tetraazaa-Analog of Phenothiazine. J Heterocyclic Chem 18: 1589-1593.

4. Von Schenker E, Herbst H (1963) Progress in drug Research pp. 269 627.

5. Kumar A, Roshanial Parashar K, Bhati SK, Yadav BP (2011) Synthesis of 10-[7,11-(2,4-disubstituted phenyl)-3-oxo-9-aminoimino-2,4diazaspiro[5,5]-phenothiazine derivatives as anti-convulsant Activity. Int J Pharm \& Biol Archives 2(1): 577-582.

6. Archana P, Rani K, Bajaj VK, Srivastava R, Chandra A, et al. (2003) Synthesis of newer Indolyl/phenothiazinyl substituted 2-oxo/ thiobarbituric acid derivatives as potent anticonvulsant agents. ArzeneimForschDrugRes 53(5): 301-306.

7. Bajaj K, Srivastava VK, Kumar A (2002) Synthesis and anti-psychotic activity of some new phenothiazine derivatives. Indian Drugs 39(4) 234-238.

8. Singh V, Khanna R, Srivastava VK, Palit G, Shanker K (1992) Synthesis and pharmacological evaluation of some phenothiazines as antidepressants. Arzneim Forsch/Drug Res 42(3): 277-280.

9. Jin HG, Sun XY, Chai KY, Piao HR, Quan SZ (2006) Anticonvulsant of some 7-alkoxy-4,5-dihydro-[1,2,4]-triazo[4,3-a]quinoline-1[2H]-ones. Bioorg Med Chem 20: 6868-6873.

10. Amaral L, Kristiansen JE, Viveiros M, Atouguia J (2001) Activity of phenothiazines against anti-biotic resistant mycobacterium tuberculosis: a review supporting further studies that may elucidate the potential use of thioridazine as anti-tuberculosis therapy. J Antimicrobial Chemotherapy 47: 505-511.

11. Bodea C, Silberg I (1968) Recent Advances in the Chemistry of Phenothiazines. Adv Heterocycl Chem 9: 321-460.

12. Hirata T, Peng G, Driscoll JS (1978) Potential CNS Antitumor agents -phenothiazine II: Fluphenazine analogs. J Pharm Sci 67(2): 157-162.
13. Amaral L, Viveros M, Molnar J (2004) Antimicrobial Activity of phenothiazines. In vivo 18(6): 725-731.

14. Godwin-Nwakwasi EU, Okoro UC, Ijeomah AO, Agbo I, Ezeokonkwo MA (2017) Palladium Catalyzed Transformation and Antimicrobial Screening of Novel Angular Azaphenothiazines. Asian J Chem 29(4): 742-748.

15. Kumar N, Sharma AK, Garg R, Yadav AK (2006) Antimicrobial screening and synthesis of some novel benzo- [a]phenothiazines and ribofuranosides. Indian J Chem 45: 747-751.

16. Shirley DA, Sen K (1961) Potential Carcinostatic Derivatives of Benzo[a]- and Benzo[b]phenothiazines. J Org Chem 26(10): 38613863.

17. Okafor CO (1986) The Chemistry and Application of Angular phenothiazine derivatives. Dyes and Pigments 7(4): 249-287.

18. Okafor CO, Okoro UC (1988) A New Synthesis of 'Three Branched' Diazaphenothiazine Dyes. Dyes \& Pigments 9: 427-442.

19. Okafor CO (1985) New Phenpthiazine Dyes and Pigments. Dyes and Pigments 6(6): 405-415.

20. Patentstorm (2004) 6,7-Disubstituted -5,8-quinolinedione Derivatives as an Antifungal Agent.

21. L Amaral, M Viveiros, J Molnar (2004) Antimicrobial Activity of Phenothiazines. In vivo 18(6): 725-731.

22. NJ Sato (1982) Heterocyclic Chem 19: 673.

23. Harinath BB, Subba RVN (1968) Synthesis of 5,6-and 5,8-quninolinequinones, Symp, Syn, Hererocycl. Compounds physiol pp. 114-118.

24. Perez C, Pauli M, Bazerque P (1990) Antibiotic Assay by the Agar-well Diffusion method. Acta Biologiae et Medicine Experimentalis 15: 113115.

25. Vardanyan RS, Hruby VJ (2006) Synthesis of Essential Drugs. Elsevier BVP 426.

26. Clinical Laboratory Standards Institute (2002) Performance standards for Antimicrobial Disc Dilution Susceptibility Tests for Bacteria isolated from Animal. 22: 13-14.

Your next submission with Juniper Publishers
will reach you the below assets
- Quality Editorial service
- Swift Peer Review
- Reprints availability
- E-prints Service
- Manuscript Podcast for convenient understanding
- Global attainment for your research
- Manuscript accessibility in different formats
( Pdf, E-pub, Full Text, Audio)
- Unceasing customer service
Track the below URL for one-step submission
https://juniperpublishers.com/online-submission.php

